\title{
Association of Preoperative Serum Levels of CEA and CA15-3 with Molecular Subtypes of Breast Cancer
}

\author{
Wenjing Zhao $\mathbb{D},{ }^{1}$ Xiaoyan Li $\mathbb{D},{ }^{2}$ Wenqing Wang $\mathbb{D},{ }^{2}$ Bing Chen $\mathbb{D},{ }^{1}$ Lijuan Wang $\mathbb{D},{ }^{1}$

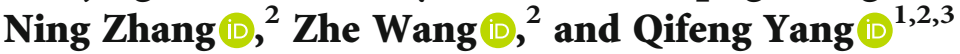 \\ ${ }^{1}$ Pathology Tissue Bank, Qilu Hospital of Shandong University, Jinan, Shandong, China \\ ${ }^{2}$ Department of Breast Surgery, General Surgery, Qilu Hospital of Shandong University, Jinan, Shandong, China \\ ${ }^{3}$ Research Institute of Breast Cancer, Shandong University, China \\ Correspondence should be addressed to Qifeng Yang; qifengy_sdu@163.com
}

Received 7 January 2021; Accepted 12 September 2021; Published 28 September 2021

Academic Editor: Anna Birková

Copyright ( 2021 Wenjing Zhao et al. This is an open access article distributed under the Creative Commons Attribution License, which permits unrestricted use, distribution, and reproduction in any medium, provided the original work is properly cited.

\begin{abstract}
Objectives. Molecular subtypes are employed as a guide for targeted treatment and important prognostic factors. This study focused on investigating the association of serum levels of CEA, CA15-3, and CA125 with clinicopathological characteristics of breast cancer to find prognostic markers for breast cancer and provide precise targeted therapy. Materials and Methods. In this study, 961 breast cancer patients with preoperative serum levels of CEA, CA15-3, and CA125 and molecular subtypes were analyzed. Cut-off values of $5 \mathrm{ng} / \mathrm{ml}, 25 \mathrm{U} / \mathrm{ml}$, and $35 \mathrm{U} / \mathrm{ml}$ were used for CEA, CA15-3, and CA125, respectively. The $\chi^{2}$ test and Fisher exact test along with logistic multivariate regression analysis were performed for investigating the correlation of CEA, CA15-3, and CA125 serum levels with molecular subtypes and associated factors. Results. An increase in the serum concentrations of CEA, CA15-3, and CA125 was discovered in 48 (4.99\%), 54 (5.62\%), and 55 (5.72\%) breast cancer patients, respectively. Univariate analysis demonstrated that the levels of CEA $(p<0.01)$ and CA15-3 $(p<0.05)$ were significantly linked with molecular types of breast cancer. Moreover, patients having larger tumor size $(p<0.01, p<0.0001$, and $p<0.05$, respectively) along with nodal metastasis $(p<0.05, p=0.0001$, and $p<0.05$, respectively) exhibited higher rates of elevated CEA, CA15-3, and CA125 levels. Status of Her-2 positive $(p<0.01)$ had a significant connection with elevated CEA levels. Multivariate analysis further indicated that molecular subtypes were independent factors associated with CEA and CA15-3 levels. Also, Her-2 status was significantly and independently related to CEA levels. Conclusion. Preoperative serum levels of CEA and CA15-3 were independently associated with molecular subtypes of breast cancer. CEA and CA15-3 might improve the prognostic prediction for patients with breast cancer and inform the selection of specific therapies. A further biological analysis is needed for investigating the relationship between Her-2 expression and CEA levels.
\end{abstract}

\section{Introduction}

Female breast cancer has now surpassed lung cancer as the leading cause of global cancer incidence in 2020, with an estimated 2.3 million new cases, representing $11.7 \%$ of all cancer cases [1]. In women, breast cancer is the most commonly diagnosed cancer and the leading cause [1]. In China, rates of breast cancer incidence and mortality have been accelerating over years and which were projected to increase modestly in the future [2]. Although there is a surge in the incidence of breast cancer, however, timely detection and the use of effective systemic adjuvant therapy while follow- ing prognostic factors have improved breast cancer prognosis $[3,4]$. Cancer antigen 15-3 (CA15-3) in addition to carcinoembryonic antigen (CEA) along with cancer antigen 125 (CA125) are extensively used in the clinical practice of breast cancer as serum tumor markers. These have been developed as noninvasive, easily available, and costeffective tumor markers for immediate diagnosis, monitoring, and prediction of breast cancer [5-7].

Breast cancer is documented as a heterogeneous disease that is further divided into molecular subtypes based on different genetic, molecular, and pathological characteristics [8]. Furthermore, breast cancer has been categorized into 
five molecular subtypes based on immunohistochemical factors which include progesterone receptor (PR), estrogen receptor (ER), Ki67 proliferation index, and human epidermal growth factor receptor 2 (Her-2). Furthermore, these five molecular subtypes are named luminal $\mathrm{A}$ in addition to luminal B (Her-2 positive) along with luminal B (Her-2 negative) apart from Her-2 overexpression as well as triplenegative [9]. Similarly, molecular subtypes along with the four immunohistochemical factors are employed as a guide for targeted treatment, including hormonal therapy, antiHer2 agent, and cytotoxic therapy [8, 10, 11]. Moreover, differences in prognosis among different subtypes of breast cancer also existed [12-14].

Further investigation is needed to identify the clinical significance of tumor markers encompassing CA125, CA15-3, and CEA. Presently, the association of molecular subtypes of breast cancer with preoperative serum levels of CA125, CA15-3, and CEA has not been elucidated yet. Therefore, this study focused on investigating the correlation of tumor markers encompassing CEA, CA15-3, and CA125 levels with molecular subtypes to improve the prognostic prediction for breast cancer and inform the appropriate therapy.

\section{Materials and Methods}

2.1. Study Patients. From January 2014 to December 2017, preoperative serum CEA, CA15-3, and CA125 concentration levels from overall 961 patients who received treatment at Qilu Hospital of Shandong University (Shandong, Jinan) were retrospectively investigated. Each recruited patient had stage I-III invasive breast cancer. Moreover, patients who had stage IV carcinoma, concurrent bilateral breast cancer, unknown histological, and tumor marker information were excluded.

2.2. Measurement of CEA, CA15-3, and CA125 Levels and Immunohistochemical Factors. Before initiating surgery, $5 \mathrm{ml}$ of peripheral blood was sampled from each recruited patient. Similarly, we employed an automatic electrochemiluminescence immunoassay system (Roche E601, Germany) for measuring preoperative serum levels of CEA, CA15-3, and CA125. Cut-off values of $5 \mathrm{ng} / \mathrm{ml}, 25 \mathrm{U} / \mathrm{ml}$, and $35 \mathrm{U} / \mathrm{ml}$ were used, respectively, for CEA, CA15-3, and CA125 as suggested levels by the manufacturer.

Positivity for ER and PR was determined when tumors with at least 1 percent of nuclear stained cells. Furthermore, we determined Her- 2 positivity by $3+$ or $2+$ score while passing through immunohistochemical evaluation, which was then passed through in situ hybridization (FISH) for further confirmation. Moreover, for Ki-67 measurement, a threshold value of 14 percent was used to distinguish tumors with low and high proliferation. According to immunohistochemical factors, molecular subtypes of breast cancer were classified as given next: First of all, luminal A consists of either both ER and PR positive or only one of them in addition to HER-2 negative along with $\mathrm{Ki}-67<14 \%$, while luminal B1 consists of either both ER and PR positive or only one of them in addition to HER-2 negative along with
$\mathrm{Ki}-67 \geq 14 \%$. Similarly, luminal B2 consists of either both ER and PR positive or only one of them in addition to HER-2 positive. Moreover, the fourth type which is HER-2 overexpression consists of both ER and PR negative in addition to HER-2 positive. The last and fifth type is triplenegative wherein all three are negative including $E R, P R$, and HER-2.

2.3. Statistical Analysis. SAS 9.4 statistical software package was used to analyze all the data. The correlation between CEA, CA125, and CA15-3 levels and immunohistochemical factors and other associated factors was examined by univariate analysis while employing the $\chi^{2}$ test and Fisher exact test. Moreover, stepwise enrollment of significant variables from univariate analysis into that of multivariate analysis was carried out. Similarly, logistic regression analysis was used for identifying independent factors correlated with the levels of CA15-3, CEA, and CA125. Two-side $p$ values were reported in this study. $p$ values that were less than 0.05 were regarded as significant.

\section{Results}

3.1. Patient Characteristics and Clinicopathological Status. Table 1 shows the clinicopathological status of all the patients enrolled in this study. The population of the study had a mean age of $51.00 \pm 10.72$ years. High levels of serum (exceeding the cut-off values) of CEA, CA15-3, and CA125 were determined in 48 (4.99\%), 54 (5.62\%), and 55 (5.72\%) breast cancer patients, respectively. Analysis of molecular subtypes of breast cancer indicated that $23.31 \%$ of patients had luminal A subtype, 39.96\% had luminal B1 (Her-2 negative) subtype, $13.22 \%$ had luminal B2 (Her-2 positive) subtype, $11.34 \%$ had Her-2 overexpression subtype, and $12.17 \%$ had triple-negative subtype.

3.2. Univariate Analysis of Association between CEA, CA153, and CA125 and Molecular Subtypes of Breast Cancer and Clinicopathological Factors. Table 2 shows the association of serum levels of CEA, CA15-3, and CA125 with the molecular subtypes of breast cancer. It was revealed by the univariate analysis that levels of CEA level $(p<0.01)$ and CA15-3 $(p<0.05)$ had a significant association with molecular subtypes of breast cancer; however, no such significant association was found for CA125 level. Similarly, Her-2 overexpression and luminal B2 (Her-2 positive) subtypes demonstrated higher rates of elevated CEA level. Meanwhile, triple-negative and luminal B2 (Her-2 positive) subtypes had a higher probability to exhibit elevation in CA15-3 level.

Tables 3, 4, and 5 show the results of the univariate analysis of the association between serum CEA, CA15-3, and CA125 levels and clinicopathological factors. Furthermore, tumor size $(p<0.01, p<0.0001$, and $p<0.05$, respectively) showed a significant association with a rise in the levels of CEA, CA15-3, and CA125. Similarly, patients with nodal metastasis $(p<0.05, p=0.0001$, and $p<0.05$, respectively) had a higher probability of elevation in the levels of CEA, CA15-3, and CA125. Additionally, the negative status of $\mathrm{PR}(p<0.01$ and $p<0.05$, respectively) had a significant 
TABLE 1: General characteristics of study population.

\begin{tabular}{|c|c|c|}
\hline Characteristics & $N$ & Percentage (\%) \\
\hline All & 961 & \\
\hline \multicolumn{3}{|l|}{ Age (years) } \\
\hline$<50$ & 454 & 47.24 \\
\hline$\geq 50$ & 507 & 52.76 \\
\hline \multicolumn{3}{|l|}{ Histologic grade } \\
\hline Grade 1 & 70 & 8.10 \\
\hline Grade 2 & 589 & 68.17 \\
\hline Grade 3 & 205 & 23.73 \\
\hline \multicolumn{3}{|l|}{ Tumor size $(\mathrm{cm})$} \\
\hline$<2$ & 516 & 57.40 \\
\hline$\geq 2$ & 383 & 42.60 \\
\hline \multicolumn{3}{|l|}{ Node status } \\
\hline N0 & 508 & 55.52 \\
\hline N1 & 407 & 44.48 \\
\hline \multicolumn{3}{|l|}{ ER } \\
\hline Negative & 251 & 26.12 \\
\hline Positive & 710 & 73.78 \\
\hline \multicolumn{3}{|l|}{ PR } \\
\hline Negative & 292 & 30.42 \\
\hline Positive & 669 & 69.58 \\
\hline \multicolumn{3}{|l|}{ Her-2 } \\
\hline Negative & 725 & 75.44 \\
\hline Positive & 236 & 24.56 \\
\hline \multicolumn{3}{|l|}{ Ki67 (\%) } \\
\hline$<14$ & 257 & 26.80 \\
\hline$\geq 14$ & 702 & 73.20 \\
\hline \multicolumn{3}{|l|}{ Molecular types } \\
\hline Luminal A & 224 & 23.31 \\
\hline Luminal B1 & 384 & 39.96 \\
\hline Luminal B2 & 127 & 13.22 \\
\hline Her-2+ & 109 & 11.34 \\
\hline Triple-negative & 117 & 12.17 \\
\hline \multicolumn{3}{|l|}{ CEA (ng/ml) } \\
\hline$<5$ & 913 & 95.01 \\
\hline$\geq 5$ & 48 & 4.99 \\
\hline \multicolumn{3}{|l|}{ CA153 (U/ml) } \\
\hline$<25$ & 907 & 94.38 \\
\hline$\geq 25$ & 54 & 5.62 \\
\hline \multicolumn{3}{|l|}{ CA125 (U/ml) } \\
\hline$<35$ & 906 & 94.28 \\
\hline$\geq 35$ & 55 & 5.72 \\
\hline
\end{tabular}

Luminal B1: ER+/PR+, Her-2 negative; Luminal B2: ER+/PR+, Her-2 positive; Her-2+: Her-2 overexpression.

association with serum levels of CA15-3 and CA125. Furthermore, patients with breast cancer aged 50 years and above $(p<0.05)$ and with the status of Her-2 positive $(p<0.01)$ exhibited higher rates of elevated CEA level. Also, patients with a negative status of ER and higher histological grade tend to have an elevated level of CA15-3. Moreover, the Ki67 value was not significantly associated with all three tumor markers.

3.3. Multivariate Analysis of the Association between CEA, CA15-3, and CA125 and Molecular Subtypes of Breast Cancer and Clinicopathological Factors. Multivariate logistic regression analysis of the association between the serum levels of CA15-3, CEA, and CA125 and related factors is shown in Table 6. Model 1 included age, tumor size, and molecular type, while in model 2, age, tumor size, and Her-2 status were included. Analysis of these two models showed that age, tumor size, molecular type, and Her-2 status were independent factors associated with CEA level. As a reference to the Her-2 overexpression subtype, luminal B1 exhibited a lower risk of elevated CEA level $(\mathrm{OR}=0.386$, $95 \% \mathrm{CI}=0.163-0.918, p<0.05)$. Moreover, patients with Her-2 positive status were more likely to have an elevated CEA level.

Model 3 incorporated histologic grade, tumor size, node status, and molecular type. Model 4 added ER and PR status, while the molecular type was excluded. Results of models 3 and 4 indicated that the size of the tumor along with node status and molecular type was fundamentally and independently related to the CA15-3 level. Compared to the luminal B2 subtype, luminal B1 exhibited a lower risk of having a higher CA15-3 level.

Model 5 included node status, tumor size, and PR status, which identified that both node status and PR status were independent factors of having an elevated CA125 level.

\section{Discussion}

In our present study, 961 patients carrying an invasive form of breast cancer were recruited to investigate the clinical importance of identifying the preoperative serum levels of various tumor markers such as CEA, CA15-3, and CA125. This study also focused on investigating the association between levels of CEA, CA15-3, and CA125 and different molecular subtypes of breast cancer. Therefore, it was unveiled by the results that high serum levels of both CEA and CA15-3 were independently and substantially related to molecular subtypes of breast cancer.

Our study hypothesis, patient characteristics, and statistical analysis methods were referring to the guideline of reporting recommendations for tumor marker prognostic studies(REMARK) [15]. There are limited studies available on the association of CEA, CA15-3, and CA125 levels with that of the molecular subtypes of breast cancer. Wu et al. [16] reported that patients with the Her-2 overexpression subtype had a higher level of CEA than the other 3 subtypes, while in the study of $\mathrm{Li}$ et al. [17], luminal A subtype presents a significant high level of CEA. There was no significant difference of CA15-3 level between molecular subtypes in these two studies [16, 17]. The results of the other two studies $[18,19]$ unveiled that levels of CEA and CA15-3 were not significantly related to molecular subtypes. In our current study, luminal B2 (ER and/or PR positive, Her-2 positive) and Her-2 overexpression subtypes demonstrated higher rates of elevated CEA level, and triple- 
TABLE 2: Correlation between serum CEA, CA15-3, and CA125 levels and molecular subtypes in breast cancer.

\begin{tabular}{|c|c|c|c|c|c|c|}
\hline Tumor marker & Luminal A $(n(\%))$ & Luminal B1 $(n(\%))$ & Luminal B2 $(n(\%))$ & $\operatorname{Her}-2+(n(\%))$ & Triple-negative $(n(\%))$ & $p$ value \\
\hline CEA (ng/ml) & & & & & & $0.0194^{*}$ \\
\hline$<5$ & $213(95.09)$ & $371(96.61)$ & $117(92.13)$ & $98(89.91)$ & $114(97.44)$ & \\
\hline$\geq 5$ & $11(4.91)$ & $13(3.39)$ & $10(7.87)$ & $11(10.09)$ & $3(2.56)$ & \\
\hline CA15-3 (U/ml) & & & & & & $0.0007^{* * *}$ \\
\hline$<25$ & $216(96.43)$ & $371(96.61)$ & $114(89.76)$ & $103(94.50)$ & $103(88.03)$ & \\
\hline$\geq 25$ & $8(3.57)$ & $13(3.39)$ & $13(10.24)$ & $6(5.50)$ & $14(11.97)$ & \\
\hline CA125 (U/ml) & & & & & & 0.2605 \\
\hline$<35$ & $213(95.09)$ & $363(94.53)$ & $121(95.28)$ & $104(95.41)$ & $105(89.74)$ & \\
\hline$\geq 35$ & $11(4.91)$ & $21(5.47)$ & $6(4.72)$ & $5(4.59)$ & $12(10.26)$ & \\
\hline
\end{tabular}

Luminal B1: ER+/PR+, Her-2 negative; Luminal B2: ER+/PR+, Her-2 positive; Her-2+: Her-2 overexpression. ${ }^{*} p<0.05$ and ${ }^{* * *} p<0.001$.

TABle 3: Correlation between serum CEA level and clinicopathological factors.

\begin{tabular}{|c|c|c|c|}
\hline Characteristic & CEA negative $(n(\%))$ & CEA positive $(n(\%))$ & $p$ value \\
\hline Age (years) & & & $<0.0001^{* * *}$ \\
\hline$<50$ & $445(98.02)$ & $9(1.98)$ & \\
\hline$\geq 50$ & $468(92.31)$ & $39(7.69)$ & \\
\hline Histologic grade & & & 0.9583 \\
\hline Grade 1 & $67(95.71)$ & $3(4.29)$ & \\
\hline Grade 2 & $563(95.59)$ & $26(4.41)$ & \\
\hline Grade 3 & $195(95.12)$ & $10(4.88)$ & \\
\hline Tumor size $(\mathrm{cm})$ & & & $0.0031^{* *}$ \\
\hline$<2$ & $502(97.29)$ & $14(2.71)$ & \\
\hline$\geq 2$ & $356(92.95)$ & $27(7.05)$ & \\
\hline Node status & & & $0.0446^{*}$ \\
\hline No & $491(96.65)$ & $17(3.35)$ & \\
\hline N1 & $382(93.86)$ & $25(6.14)$ & \\
\hline ER & & & 0.4064 \\
\hline Negative & $236(94.02)$ & $15(5.98)$ & \\
\hline Positive & $677(95.35)$ & $33(4.65)$ & \\
\hline PR & & & 0.2647 \\
\hline Negative & $274(93.84)$ & $18(6.16)$ & \\
\hline Positive & $639(95.52)$ & $30(4.48)$ & \\
\hline Her-2 & & & $0.0030^{* *}$ \\
\hline Negative & $698(96.28)$ & $27(3.72)$ & \\
\hline Positive & $215(91.10)$ & $21(8.90)$ & \\
\hline Ki67 (\%) & & & 0.8681 \\
\hline$<14$ & $245(95.33)$ & $12(4.67)$ & \\
\hline$\geq 14$ & $666(94.87)$ & $36(5.13)$ & \\
\hline
\end{tabular}

negative subtype exhibited a lower level of elevated CEA, which were in harmony with the study of $\mathrm{Wu}$ et al. [16]. Also, we discovered that a significantly higher CA15-3 level was seen in luminal B2 and triple-negative subtypes. In our study, we further identified molecular subtype retained its significant association with CEA and CA15-3 levels even when adjustments were made for other known related clinicopathological factors. Serum level of CA125 was not found to be significantly different in molecular subtypes. Previous studies have shown that elevated level of CEA was correlated to Her-2 positive status $[18,20,21]$. Besides, we also observed a significant difference of higher CEA level in Her-2 status but not in ER, PR status, and Ki67 value. The difference of elevated CEA level between molecular types may chiefly be caused by the significant correlation between higher CEA levels and Her-2 status. Her-2 amplification had been identified in human breast cancer cells which may result in a more aggressive tumor type clinically and 
TABLE 4: Correlation between serum CA15-3 level and clinicopathological factors.

\begin{tabular}{|c|c|c|c|}
\hline Characteristic & $\begin{array}{l}\text { CA15-3 negative } \\
(n(\%))\end{array}$ & $\begin{array}{c}\text { CA15-3 positive } \\
(n(\%))\end{array}$ & $p$ value \\
\hline Age (years) & & & 0.4001 \\
\hline$<50$ & $432(95.15)$ & $22(4.85)$ & \\
\hline$\geq 50$ & 475 (93.69) & $32(6.31)$ & \\
\hline $\begin{array}{l}\text { Histologic } \\
\text { grade }\end{array}$ & & & $0.0223^{*}$ \\
\hline Grade 1 & $69(98.57)$ & $1(1.43)$ & \\
\hline Grade 2 & $562(95.42)$ & $27(4.58)$ & \\
\hline Grade 3 & 187 (91.22) & $18(8.78)$ & \\
\hline $\begin{array}{l}\text { Tumor size } \\
(\mathrm{cm})\end{array}$ & & & $<0.0001^{* * *}$ \\
\hline$<2$ & 503 (97.48) & $13(2.52)$ & \\
\hline$\geq 2$ & $348(90.86)$ & $35(9.14)$ & \\
\hline Node status & & & $0.0001^{* * *}$ \\
\hline N0 & $493(97.05)$ & $15(2.95)$ & \\
\hline N1 & 371 (91.15) & $36(8.85)$ & \\
\hline ER & & & $0.0036^{* *}$ \\
\hline Negative & $227(90.44)$ & $24(9.56)$ & \\
\hline Positive & $680(95.77)$ & $30(4.23)$ & \\
\hline $\mathrm{PR}$ & & & $0.0056^{* *}$ \\
\hline Negative & $266(91.10)$ & $26(8.90)$ & \\
\hline Positive & $641(95.81)$ & $28(4.19)$ & \\
\hline Her2 & & & 0.0729 \\
\hline Negative & $690(95.17)$ & $35(4.83)$ & \\
\hline Positive & 217 (91.95) & $19(8.05)$ & \\
\hline Ki67 (\%) & & & 0.2050 \\
\hline$<14$ & 247 (96.11) & $10(3.89)$ & \\
\hline$\geq 14$ & $658(93.73)$ & $44(6.27)$ & \\
\hline
\end{tabular}

significantly related to survival in patients with breast cancer [22-26]. Her-2 and serum CEA level are both widely used markers for the prognosis of breast cancer. The biological behavior between elevated CEA level and Her-2 overexpression needs to be further explored.

Previous studies have already shown the association between tumor size, which represents the tumor burden, and elevated levels of CEA or CA15-3 [16, 17, 21, 27]. In the present study, we also identified the association between tumor size and elevation in the levels of CEA, CA15-3, and CA125. Meanwhile, tumor size was further identified as an independent factor associated with CEA, CA15-3, and CA125 levels in the multivariate analysis. Significantly high levels of CEA or CA 15-3 were exhibited in patients suffering from a later stage of breast cancer than those with early disease $[17,28]$. In agreement with previous reports [21, 29, 30 , we also demonstrated that elevated preoperative serum level of CA15-3 was related to poor histological grade in breast cancer. However, the relationship between tumor biological index and CEA, CA15-3, and CA125 levels is not clearly confirmed yet $[6,31]$.
TABLE 5: Correlation between serum CA125 level and clinicopathological factors.

\begin{tabular}{|c|c|c|c|}
\hline Characteristic & $\begin{array}{l}\text { CA125 negative } \\
(n(\%))\end{array}$ & $\begin{array}{l}\text { CA125 positive } \\
(n(\%))\end{array}$ & $p$ value \\
\hline Age (years) & & & 0.1674 \\
\hline$<50$ & $423(93.17)$ & $31(6.83)$ & \\
\hline$\geq 50$ & $483(95.27)$ & $24(4.73)$ & \\
\hline Histologic grade & & & 0.6247 \\
\hline Grade 1 & $65(92.86)$ & $5(7.14)$ & \\
\hline Grade 2 & $558(94.74)$ & $31(5.26)$ & \\
\hline Grade 3 & $191(93.17)$ & $14(6.83)$ & \\
\hline Tumor size $(\mathrm{cm})$ & & & $0.0296^{*}$ \\
\hline$<2$ & $494(95.74)$ & $22(4.26)$ & \\
\hline$\geq 2$ & $353(92.17)$ & $30(7.83)$ & \\
\hline Node status & & & $0.0157^{*}$ \\
\hline No & $487(95.87)$ & $21(4.13)$ & \\
\hline N1 & $374(91.89)$ & $33(8.11)$ & \\
\hline ER & & & 0.0825 \\
\hline Negative & $231(92.03)$ & $20(7.97)$ & \\
\hline Positive & $675(95.07)$ & $35(4.93)$ & \\
\hline $\mathrm{PR}$ & & & $0.0341^{*}$ \\
\hline Negative & $268(91.78)$ & $24(8.22)$ & \\
\hline Positive & $638(95.37)$ & $31(4.63)$ & \\
\hline Her2 & & & 0.5191 \\
\hline Negative & $681(93.93)$ & $44(6.07)$ & \\
\hline Positive & $225(95.34)$ & $11(4.66)$ & \\
\hline \multicolumn{4}{|l|}{ Ki67 (\%) } \\
\hline$<14$ & $244(94.94)$ & $13(5.06)$ & 0.5855 \\
\hline$\geq 14$ & $660(94.02)$ & $42(5.98)$ & \\
\hline $\begin{array}{l}\text { Molecular } \\
\text { subtype }\end{array}$ & & & 0.2605 \\
\hline Luminal A & $213(95.09)$ & $11(4.91)$ & \\
\hline Luminal B1 & $363(94.53)$ & $21(5.47)$ & \\
\hline Luminal B2 & $121(95.28)$ & $6(4.72)$ & \\
\hline $\begin{array}{l}\text { Her2 } \\
\text { overexpression }\end{array}$ & $104(95.41)$ & $5(4.59)$ & \\
\hline Triple-negative & $105(89.74)$ & $12(10.26)$ & \\
\hline
\end{tabular}

In our present study, we identified that patients carrying high serum levels of CEA and CA15-3 were more likely to exhibit metastasis status of lymph node, which was in harmony with the studies of $\mathrm{Wu}$ et al. [16, 17, 32]. Lee et al. [21] also reported the relation between CA15-3 level and lymph node metastasis status. Our study also indicated that CA125 was significantly associated with node status and CA15-3 and CA125 were independent factors related to node status. Cancer antigen in serum implies the possibility of tumor vascularization and micrometastases [33]. Also, Kim et al. measured the concentration of CA15-3 in washout of fine-needle aspirates (FNA) from the axillary lymph node of patients having breast cancer, identifying that patients diagnosed with positive metastasis had remarkably elevated 
TABLE 6: Multiple logistic regression analysis of the association of clinicopathological characteristics with serum CEA, CA15-3, and CA125 levels.

\begin{tabular}{|c|c|c|c|}
\hline Characteristic & OR & $\mathrm{CI}$ & $p$ value \\
\hline \multicolumn{4}{|c|}{ Model 1 CEA } \\
\hline \multicolumn{4}{|l|}{ Age (years) } \\
\hline$\geq 50$ vs. $<50$ & 4.319 & $2.040-9.143$ & $0.0001^{* * *}$ \\
\hline \multicolumn{4}{|l|}{ Tumor size $(\mathrm{cm})$} \\
\hline$\geq 2$ vs. $<2$ & 2.364 & $1.185-4.715$ & $0.0146^{*}$ \\
\hline \multicolumn{4}{|l|}{ Node status } \\
\hline N1 vs. N0 & 1.770 & $0.918-3.413$ & 0.0885 \\
\hline \multicolumn{4}{|l|}{ Molecular type } \\
\hline Luminal A vs. Her2+ & 0.679 & $0.273-1.689$ & 0.4056 \\
\hline Luminal B1 vs. Her2+ & 0.386 & $0.163-0.918$ & $0.0313^{*}$ \\
\hline Luminal B2 vs. Her2+ & 0.933 & $0.365-2.382$ & 0.8840 \\
\hline Triple-negative vs. Her2+ & 0.294 & $0.078-1.110$ & 0.0710 \\
\hline \multicolumn{4}{|c|}{ Model 2 CEA } \\
\hline \multicolumn{4}{|l|}{ Age (years) } \\
\hline$\geq 50$ vs. $<50$ & 4.299 & $2.036-9.079$ & $0.0001^{* * *}$ \\
\hline \multicolumn{4}{|l|}{ Tumor size $(\mathrm{cm})$} \\
\hline$\geq 2$ vs. $<2$ & 2.262 & $1.141-4.482$ & $0.0193^{*}$ \\
\hline \multicolumn{4}{|l|}{ Node status } \\
\hline N1 vs. N0 & 1.749 & $0.910-3.359$ & 0.0934 \\
\hline \multicolumn{4}{|l|}{ Her2 } \\
\hline \multirow[t]{2}{*}{ Positive vs. negative } & 2.156 & $1.169-3.979$ & $0.0139^{*}$ \\
\hline & \multicolumn{3}{|c|}{ Model 3 CA15-3 } \\
\hline \multicolumn{4}{|l|}{ Histologic grade } \\
\hline Grade 2 vs. Grade 1 & 1.717 & $0.213-13.862$ & 0.6120 \\
\hline Grade 3 vs. Grade 1 & 2.209 & $0.228-18.062$ & 0.5260 \\
\hline \multicolumn{4}{|l|}{ Tumor size $(\mathrm{cm})$} \\
\hline$\geq 2$ vs. $<2$ & 3.019 & $1.538-5.926$ & $0.0013^{* *}$ \\
\hline \multicolumn{4}{|l|}{ Node status } \\
\hline N1 vs. N0 & 2.633 & $1.387-5.001$ & $0.0031^{* *}$ \\
\hline \multicolumn{4}{|l|}{ Molecular type } \\
\hline Luminal A vs. luminal B2 & 0.457 & $0.173-1.203$ & 0.1127 \\
\hline Luminal B1 vs. luminal B2 & 0.349 & $0.154-0.791$ & $0.0117^{*}$ \\
\hline Her2+ vs. luminal B2 & 0.478 & $0.170-1.346$ & 0.1620 \\
\hline \multirow[t]{2}{*}{ Triple-negative vs. luminal B2 } & 1.293 & $0.536-3.119$ & 0.5676 \\
\hline & Mode & & \\
\hline \multicolumn{4}{|l|}{ Histologic grade } \\
\hline Grade 2 vs. Grade 1 & 1.765 & $0.229-13.586$ & 0.5851 \\
\hline Grade 3 vs. Grade 1 & 2.244 & $0.271-18.593$ & 0.4536 \\
\hline \multicolumn{4}{|c|}{ Tumor size $(\mathrm{cm})$} \\
\hline$\geq 2$ vs. $<2$ & 2.865 & $1.464-5.608$ & $0.0021^{* *}$ \\
\hline \multicolumn{4}{|l|}{ Node status } \\
\hline N1 vs. N0 & 2.720 & $1.440-5.140$ & $0.0020^{* *}$ \\
\hline \multicolumn{4}{|l|}{ ER } \\
\hline Positive vs. negative & 0.607 & $0.242-1.523$ & 0.2874 \\
\hline \multicolumn{4}{|l|}{$\mathrm{PR}$} \\
\hline Positive vs. negative & 0.794 & $0.327-1.924$ & 0.6088 \\
\hline
\end{tabular}


TABLE 6: Continued.

\begin{tabular}{|c|c|c|c|}
\hline Characteristic & OR & $\mathrm{CI}$ & $p$ value \\
\hline \multicolumn{4}{|c|}{ Model 5 CA125 } \\
\hline \multicolumn{4}{|l|}{ Tumor size $(\mathrm{cm})$} \\
\hline$\geq 2$ vs. $<2$ & 1.550 & $0.863-2.782$ & 0.1423 \\
\hline \multicolumn{4}{|l|}{ Node status } \\
\hline N1 vs. N0 & 1.903 & $1.070-3.386$ & $0.0286^{*}$ \\
\hline \multicolumn{4}{|l|}{$\mathrm{PR}$} \\
\hline Positive vs. negative & 0.567 & $0.323-0.996$ & $0.0486^{*}$ \\
\hline
\end{tabular}

${ }^{*} p<0.05,{ }^{* *} p<0.01$, and ${ }^{* * *} p<0.001$.

FNA concentrations of CA-15-3 as compared to patients without lymph node metastasis [34]. This may partly explain the positive relationship between elevated CA15-3 and CA125 levels and metastasis status of the lymph node. The biological mechanism of lymph node and CA15-3 and CA125 levels needs to be further investigated.

There were a few limitations to the present study. First of all, this was a single-center retrospective analysis with bias in subject selection. Furthermore, only qualitative analysis of serum levels was focused for CEA, CA15-3, and CA125. Therefore, further prospective investigation in addition to quantitative analysis of CEA, CA15-3, and CA125 levels is needed to be carried out.

\section{Conclusion}

In conclusion, the study demonstrated that preoperative serum levels of CEA and CA15-3 had an independent association with molecular subtypes of breast cancer with high level of CEA in Her-2-positive patients (luminal B Her-2 positive and Her-2 overexpression). The study also explored the indicated significance of serum tumor markers in larger tumor size, Her-2 overexpression, metastasis status of lymph node, older age, and poor histological grade. Further biological analysis and prospective study are needed to be carried out for Her-2 expression and serum levels of CEA.

\section{Data Availability}

All data needed to evaluate the conclusions in the paper are present in the paper.

\section{Ethical Approval}

The procedures adopted in this study including human participants followed the ethical standards of the national research committee/institution and the 1964 Helsinki declaration and its amendments made in later stages or comparable ethical standards.

\section{Consent}

All the individuals participating in the study provided their informed consent.

\section{Conflicts of Interest}

The authors of this study declare no conflict of interests.

\section{Acknowledgments}

This work was supported by the National Key Research and Development Program (No. 2020YFA0712400), the Special Foundation for Taishan Scholars (No. ts20190971), the National Natural Science Foundation of China (No. 81874119 and No. 82072912), the Special Support Plan for National High Level Talents (Ten Thousand Talents Program W01020103), the Foundation from Clinical Research Center of Shandong University (No. 2020SDUCRCA015), the Qilu Hospital Clinical New Technology Developing Foundation (No. 2018-7 and No. 2019-3) to Qifeng Yang, the China Postdoctoral Science Foundation (No. 2017M612292) to Wenjing Zhao, the National Natural Science Foundation of China (No. 81702602) to Bing Chen, the National Natural Science Foundation of China (No. 82171734) to Lijuan Wang, the National Natural Science Foundation of China (No. 81972475), the Key Research and Development Program of Shandong Province (2019GSF108140), and the China Postdoctoral Science Foundation (2019T120593 and 2018M630787) to Ning Zhang.

\section{References}

[1] H. Sung, J. Ferlay, R. L. Siegel et al., "Global cancer statistics 2020: GLOBOCAN estimates of incidence and mortality worldwide for 36 cancers in 185 countries," CA: a Cancer Journal for Clinicians, vol. 71, no. 3, pp. 209-249, 2021.

[2] S. Lei, R. Zheng, S. Zhang et al., "Breast cancer incidence and mortality in women in China: temporal trends and projections to 2030," Cancer Biology \& Medicine, vol. 18, no. 3, pp. 900 909, 2021.

[3] L. de Cock, J. Heylen, A. Wildiers et al., "Detection of secondary metastatic breast cancer by measurement of plasma CA 15.3," ESMO Open, vol. 6, no. 4, article 100203, 2021.

[4] R. C. Coombes, H. Tovey, L. Kilburn et al., "Effect of celecoxib vs placebo as adjuvant therapy on disease-free survival among patients with breast Cancer," JAMA Oncology, vol. 7, no. 9, pp. 1291-1301, 2021.

[5] W. Ma, X. Wang, G. Xu et al., "Distant metastasis prediction via a multi-feature fusion model in breast cancer," Aging 
(Albany NY), vol. 12, no. 18, article 103630, pp. 18151-18162, 2020.

[6] R. Yerushalmi, S. Tyldesley, H. Kennecke et al., "Tumor markers in metastatic breast cancer subtypes: frequency of elevation and correlation with outcome," Annals of Oncology: official journal of the European Society for Medical Oncology, vol. 23, no. 2, pp. 338-345, 2012.

[7] F. C. Bidard, D. Hajage, T. Bachelot et al., "Assessment of circulating tumor cells and serum markers for progression-free survival prediction in metastatic breast cancer: a prospective observational study," Breast Cancer Research: BCR, vol. 14, no. 1, p. R29, 2012.

[8] K. M. Turner, S. K. Yeo, T. M. Holm, E. Shaughnessy, and J. L. Guan, "Heterogeneity within molecular subtypes of breast cancer," American Journal of Physiology. Cell Physiology, vol. 321, no. 2, pp. C343-C354, 2021.

[9] H. J. Burstein, G. Curigliano, B. Thürlimann et al., "Customizing local and systemic therapies for women with early breast cancer: the St. Gallen International Consensus Guidelines for treatment of early breast cancer 2021," Annals of Oncology: official journal of the European Society for Medical Oncology, vol. S0923-7534, no. 21, pp. 2104-2109, 2021.

[10] G. Farshid and D. Walters, "Molecular subtypes of screendetected breast cancer," Breast cancer research and treatment, vol. 172, no. 1, pp. 191-199, 2018.

[11] for the MINDACT investigators, G. Viale, F. A. de Snoo et al., "Immunohistochemical versus molecular (BluePrint and MammaPrint) subtyping of breast carcinoma. Outcome results from the EORTC 10041/BIG 3-04 MINDACT trial," Breast Cancer Research and Treatment, vol. 167, no. 1, pp. 123-131, 2018.

[12] B. Z. Clark, A. Onisko, B. Assylbekova, X. Li, R. Bhargava, and D. J. Dabbs, "Breast cancer global tumor biomarkers: a quality assurance study of intratumoral heterogeneity," Modern Pathology: an official journal of the United States and Canadian Academy of Pathology, Inc, vol. 32, no. 3, pp. 354-366, 2019.

[13] A. Prat and C. M. Perou, "Deconstructing the molecular portraits of breast cancer," Molecular Oncology, vol. 5, no. 1, pp. 5-23, 2011.

[14] Y. Li, S. Lu, Y. Zhang, S. Wang, and H. Liu, "Loco-regional recurrence trend and prognosis in young women with breast cancer according to molecular subtypes: analysis of 1099 cases," World Journal of Surgical Oncology, vol. 19, no. 1, p. 113, 2021.

[15] W. Sauerbrei, S. E. Taube, L. M. McShane, M. M. Cavenagh, and D. G. Altman, "Reporting recommendations for tumor marker prognostic studies (REMARK): an abridged explanation and elaboration," Journal of the National Cancer Institute, vol. 110, no. 8, pp. 803-811, 2018.

[16] S. G. Wu, Z. Y. He, J. Zhou et al., "Serum levels of CEA and CA15-3 in different molecular subtypes and prognostic value in Chinese breast cancer," Breast, vol. 23, no. 1, pp. 88-93, 2014.

[17] J. Li, L. Liu, Z. Feng et al., "Tumor markers CA15-3, CA125, CEA and breast cancer survival by molecular subtype: a cohort study," Breast Cancer, vol. 27, no. 4, pp. 621-630, 2020.

[18] X. Li, D. Dai, B. Chen, H. Tang, X. Xie, and W. Wei, "Determination of the prognostic value of preoperative CA15-3 and CEA in predicting the prognosis of young patients with breast cancer," Oncology Letters, vol. 16, no. 4, pp. 4679-4688, 2018.
[19] M. Araz, I. Beypinar, S. Kazan, F. Inci, M. Celiker, and M. Uysal, "Are preoperative serum CA15-3 levels different in breast cancer subgroups?," Current Problems in Cancer, vol. 43, no. 2, pp. 115-122, 2019.

[20] M. Imamura, T. Morimoto, T. Nomura et al., "Independent prognostic impact of preoperative serum carcinoembryonic antigen and cancer antigen 15-3 levels for early breast cancer subtypes," World Journal of Surgical Oncology, vol. 16, no. 1, p. 26, 2018.

[21] J. S. Lee, S. Park, J. M. Park, J. H. Cho, S. I. Kim, and B. W. Park, "Elevated levels of preoperative CA 15-3 and CEA serum levels have independently poor prognostic significance in breast cancer," Annals of Oncology: official journal of the European Society for Medical Oncology, vol. 24, no. 5, pp. 12251231, 2013.

[22] R. Bradley, J. Braybrooke, R. Gray et al., "Trastuzumab for early-stage, HER2-positive breast cancer: a meta-analysis of 13864 women in seven randomised trials," The Lancet Oncology, vol. 22, no. 8, pp. 1139-1150, 2021.

[23] S. Cen, Z. Liu, H. Pan, and W. Han, "Clinicopathologic features and treatment advances in cancers with HER2 alterations," Biochimica et Biophysica Acta. Reviews on Cancer, vol. 1876, no. 2, article 188605, 2021.

[24] L. Yang, Y. Li, A. Bhattacharya, and Y. Zhang, "A recombinant human protein targeting HER2 overcomes drug resistance in HER2-positive breast cancer," Science Translational Medicine, vol. 11, no. 476, 2019.

[25] Y. Fan, Y. Wang, L. He, S. Imani, and Q. Wen, "Clinical features of patients with HER2-positive breast cancer and development of a nomogram for predicting survival," ESMO Open, vol. 6, no. 4, article 100232, 2021.

[26] M. V. Dieci, P. Conte, G. Bisagni et al., "Association of tumorinfiltrating lymphocytes with distant disease-free survival in the ShortHER randomized adjuvant trial for patients with early HER2+ breast cancer," Annals of Oncology: official journal of the European Society for Medical Oncology, vol. 30, no. 3, pp. 418-423, 2019.

[27] M. Lian, C. Zhang, D. Zhang et al., "The association of five preoperative serum tumor markers and pathological features in patients with breast cancer," Journal of Clinical Laboratory Analysis, vol. 33, no. 5, article e22875, 2019.

[28] M. Khushk, A. Khan, A. Rehman et al., "The role of tumor markers: carcinoembryonic antigen and cancer antigen 15-3 in patients with breast cancer," Cureus, vol. 13, no. 7 , article e16298, 2021.

[29] R. Molina, J. M. Augé, J. M. Escudero et al., "Evaluation of tumor markers (HER-2/neu oncoprotein, CEA, and CA 15.3) in patients with locoregional breast cancer: prognostic value," Tumour Biology: the journal of the International Society for Oncodevelopmental Biology and Medicine, vol. 31, no. 3, pp. 171-180, 2010.

[30] R. Molina, J. M. Auge, B. Farrus et al., "Prospective evaluation of carcinoembryonic antigen (CEA) and carbohydrate antigen 15.3 (CA 15.3) in patients with primary locoregional breast cancer," Clinical Chemistry, vol. 56, no. 7, pp. 1148-1157, 2010.

[31] F. Andre, N. Ismaila, N. L. Henry et al., "Use of biomarkers to guide decisions on adjuvant systemic therapy for women with early-stage invasive breast cancer: ASCO clinical practice guideline update-integration of results from TAILORx," Journal of Clinical Oncology: official journal of the American Society of Clinical Oncology, vol. 37, no. 22, pp. 1956-1964, 2019. 
[32] S. G. Wu, Z. Y. He, H. Y. Ren et al., "Use of CEA and CA15-3 to predict axillary lymph node metastasis in patients with breast cancer," Journal of Cancer, vol. 7, no. 1, pp. 37-41, 2016.

[33] A. Goussia, N. Simou, F. Zagouri et al., "Associations of angiogenesis-related proteins with specific prognostic factors, breast cancer subtypes and survival outcome in early-stage breast cancer patients. A Hellenic Cooperative Oncology Group (HeCOG) trial," PLoS One, vol. 13, no. 7, article e0200302, 2018.

[34] M. J. Kim, B. W. Park, J. B. Lim et al., "Axillary lymph node metastasis: CA-15-3 and carcinoembryonic antigen concentrations in fine-needle aspirates for preoperative diagnosis in patients with breast cancer," Radiology, vol. 254, no. 3, pp. 691-697, 2010. 